\title{
Analysis of Axial Pushing Force by New Machining Technology for Engineering Ceramics Based on Edge-chipping Effect
}

\author{
SUN $\mathrm{Yi}^{1}$, WANG Long ${ }^{2,{ }^{*}}$,Tian Xinli ${ }^{2}$ \\ ${ }^{1}$ Department of Information Engineering, Academy of Armored Force Engineering, Beijing 100072, \\ China \\ ${ }^{2}$ National Key Laboratory for Equipment Remanufacturing, Academy of Armored Force \\ Engineering, Beijing 100072, China
}

Keywords: Machining technology; Edge chipping; Axial push force

\begin{abstract}
The cutting-pushing machining based on edge chipping effect is a kind of innovative machining technology, it applies stress concentration effect of precast construction mutation and broken edge effect of crack on new edge surface to process. Aim at the total difference between new machining technique and traditional contact processing, it deeply discussed the characterization of features during the machining process of Axial push force by establishment of feasible experimental scheme.
\end{abstract}

\section{Introduction}

Engineering ceramics is a hard and brittle materials. it is more sensitive to processing crack, residual tensile stress and other defects than metal material. The machining damage of engineering ceramics including cracking and fragmentation, and they become the processing problem of engineering ceramics due to randomness and difficult to be control[1,2].However, The "harm" and "benefit" of crack can be transformed each other in certain conditions. The push collapse to drive crack propagation machining technology based on the edge chipping effect make full use of the stress concentration effect[3] which is the common cause by prefabricated defect and the structure change of workpiece surface, as well as the edge chipping effect[4,5].

\section{Experimental Method}

The experiment applies Vertical 4 Axial machining center BV-75 made from Beijing Mechanical and Electrical Institute as experiment platform during the process of pushing. It also applies SDC-C4F, High-performance strain gauge universal milling drilling grinding dynamometer, made from Beihang University, which is mainly composed of a circular table and dynamometer body, the vertical component $\mathrm{Fz}$ measurement range of $0 \sim 4500 \mathrm{~N}$.

The experiment uses reaction sintering of Si3N4 specimen material size with a diameter of $\varphi=26$ $\mathrm{mm}$, height $\mathrm{H}=60 \mathrm{~mm}$. The main performance parameters of the material: density $\rho=2.73 \mathrm{~g} / \mathrm{cm} 3$, hardness HRA $=85$, the modulus of elasticity $\mathrm{E}=160 \mathrm{Gpa}$, breaking strength KIC $=2.85 \mathrm{MPa} . \mathrm{m} 1$ / 2.

Work at a constant speed 150r / min is rotated. Experiment applies L16 (45) orthogonal table, pushing the tool against axial feed velocity $\mathrm{V}$, the flange thickness $\mathrm{A}$, the groove depth $\mathrm{H}$ of the three major processing parameters arrange 16 set of experiments, the measured three times at each set of parameters for each machining reservations mean axial flange after pushing force. Other factors and orthogonal experiments involving as shown in Table 1. 
Table 1 Elements and Standard of Orthogonal Experiment

\begin{tabular}{cccc}
\hline Elements & $\begin{array}{c}\text { Axial Feeding Speed } \\
\text { V/mm.min-1 }\end{array}$ & $\begin{array}{c}\text { Depth of } \\
\text { Groove } \\
\text { H/mm }\end{array}$ & $\begin{array}{c}\text { Thickness of } \\
\text { Flange } \\
\mathbf{A} / \mathbf{m m}\end{array}$ \\
\hline 1 & 20 & 1.5 & 2 \\
2 & 50 & 2 & 2.5 \\
3 & 80 & 2.5 & 3 \\
4 & 100 & 3 & 3.5 \\
\hline
\end{tabular}

\section{Results and Discussion}

Tables 2 and Tables 3 are axial pushing force of visual analysis and variance analysis table. By range and variance ratio $\mathrm{F}$ can be informed of the processing parameters for each push Tool Wear of primary and secondary order. Wherein the turning axial feed rate, the flange thickness, groove depth ratio were 2.363,0.565,0.070 F; and wherein the axial feed rate, depth of the grooves, the flange width respective pushing force obtained were very poor as $198.392 \mathrm{~N}, 34.378 \mathrm{~N}, 91.661 \mathrm{~N}$. Influence of axial feed rate, the flange width, groove depth influence on the axial pushing forces are successively decreased, which is known in Visual Analysis Table and Variance Analysis Table.

Table 2 Visual Analysis

\begin{tabular}{|c|c|c|c|c|c|}
\hline $\mathbf{S} / \mathbf{N}$ & $\begin{array}{l}\text { Feed Speed } \\
\mathrm{V} / \mathrm{mm} / \mathrm{min}\end{array}$ & $\begin{array}{c}\text { Depth of Groo } \\
\text { H/mm }\end{array}$ & & $\begin{array}{c}\text { Thickness of } \\
\text { Flange } \\
\text { A/mm }\end{array}$ & $\begin{array}{c}\text { Axial Push Force } \\
\text { F/N }\end{array}$ \\
\hline Test1 & 1 & 1 & & 1 & 368.2038 \\
\hline Test2 & 1 & 2 & & 2 & 403.7513 \\
\hline Test3 & 1 & 3 & & 3 & 435.9827 \\
\hline Test4 & 1 & 4 & & 4 & 466.3526 \\
\hline Test5 & 2 & 1 & & 2 & 355.7387 \\
\hline Test6 & 2 & 2 & & 1 & 313.9725 \\
\hline Test7 & 2 & 3 & & 4 & 410.5561 \\
\hline Test8 & 2 & 4 & & 3 & 344.0363 \\
\hline Test9 & 3 & 1 & & 3 & 356.1195 \\
\hline Test10 & 3 & 2 & & 4 & 326.2746 \\
\hline Test11 & 3 & 3 & & 1 & 253.4084 \\
\hline Test12 & 3 & 4 & & 2 & 231.2057 \\
\hline Test13 & 4 & 1 & & 4 & 262.8918 \\
\hline Test14 & 4 & 2 & & 3 & 243.6786 \\
\hline Test15 & 4 & 3 & & 2 & 210.3065 \\
\hline Test16 & 4 & 4 & & 1 & 163.8473 \\
\hline AVG1 & 418.573 & 335.738 & & 274.858 & \\
\hline AVG2 & 356.076 & 321.919 & & 300.251 & \\
\hline AVG3 & 291.752 & 327.563 & & 344.954 & \\
\hline AVG4 & 220.181 & 301.360 & & 366.519 & \\
\hline Range & 198.392 & 34.378 & & 91.661 & \\
\hline & \multicolumn{4}{|c|}{ Table 3 Variance Analysis } & \\
\hline & Element & $\begin{array}{c}\text { Square } \\
\text { Deviations }\end{array}$ & DOF & Ratio F & \\
\hline & Feed Speed & 87075.873 & 3 & 2.363 & \\
\hline & $\begin{array}{l}\text { Depth of } \\
\text { Groove }\end{array}$ & 2580.761 & 3 & 0.070 & \\
\hline & $\begin{array}{l}\text { Thickness of } \\
\text { Flange }\end{array}$ & 20814.895 & 3 & 0.565 & \\
\hline & $\begin{array}{c}\text { Axial Push } \\
\text { Force }\end{array}$ & 110471.53 & 9 & & \\
\hline
\end{tabular}


Take pushing process of Visual analysis in Table 2 as abscissa, and under the conditions of each factor level, mean axial force pushing ordinate as vertical ordinate, plotted relationship between the processing parameters and the average axial pushing force pushing between As shown in Figure 1. Increasing axial feed rate may reduce the axial pushing force; groove depth increased, to some extent the pushing force is slightly smaller; flange thickness increased, axial pushing force becomes large.

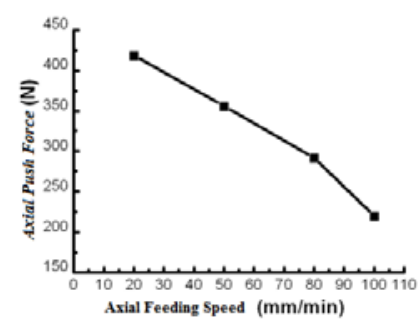

(a) Axial Feeding Speed

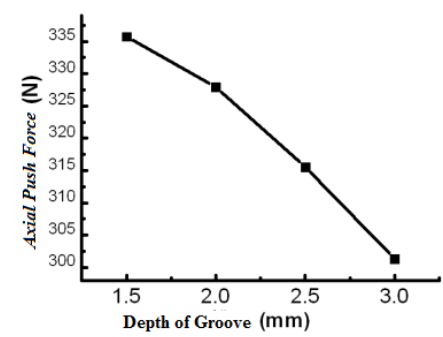

(b) Groove Depth

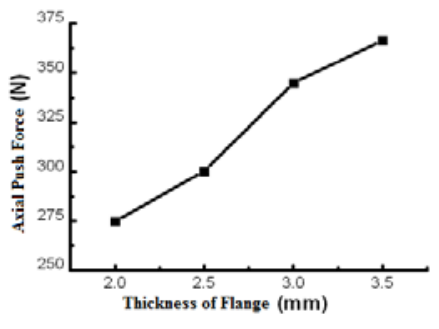

(c) Thickness of Flange

Figure 1 The impact of processing parameters on the axial pushing force

\section{Establishment of Multivariate Nonlinear Regression Model}

During the machining of ceramics cutting edge chipping - pushing process, if axial pushing force $\mathrm{F}$ with axial feed velocity $\mathrm{V}$, the flange thickness $\mathrm{A}$, the relationship groove depth $\mathrm{H}$ three main process parameters are likely to have similar metal cutting classic formula:

$$
F=c \mathrm{~A}^{m} H^{n} V^{k}
$$

By transformation, results of axial pushing force to solve the exponential regression model regression coefficients in orthogonal table are shown in Table 4.

It can uses R2 statistical test value (goodness of fit test) and F test statistic value (significance test) of each model to value reasonable degree evaluation model. Statistical test to axial pushing force of the exponential model are shown in Table 5, the exponential model better fits a given level orthogonal experiment samples, data representation of regression equation is strong.

Table 4 Regression coefficient of axial pushing force in exponential model

\begin{tabular}{cccc}
\hline $\begin{array}{c}\text { Regression } \\
\text { Coefficient }\end{array}$ & $\begin{array}{c}\text { Regression Coefficient } \\
\text { Estimates }\end{array}$ & \multicolumn{2}{c}{ Confidence Interval of RC } \\
\hline Inc & 6.7854 & {$[6.2028$} & $7.3680]$ \\
$m$ & 0.5783 & {$[0.2538$} & $0.9028]$ \\
$n$ & -0.2265 & {$[-0.4883$} & $0.0353]$ \\
$k$ & -0.3639 & {$[-0.4736$} & $-0.2542]$ \\
\hline$R^{2}=0.8552$ & $F=23.623$ & $p=0.0000<0.0001$ & s2 $=0.0155$ \\
\hline
\end{tabular}

The fitting formula of axial pushing force is:

$$
F=884.8265 A^{0.5783} H^{-0.2265} V^{-0.3639}
$$

\section{Conclusion}

The influence to the axial pushing force are individually decreased by feed of axial direction, flange width and groove depth. Axial feed rate increases, the axial pushing force is reduced; the groove depth is increased to some extent, the pushing force is slightly smaller; flange thickness increases, the axial pushing force becomes large. 


\section{Acknowledgment}

The authors are grateful for the financial aid given by the Natural Science Foundation of China (Grant nos. 51475474).

\section{References}

[1]. Tang XJ, Tian XL, Wu ZY,et al. Research progress of edge chipping behavior and mechanism of engineering ceramics[J].China Mechanical Engineering,2010,21(1):114-119

[2]. Tian Xl, Yu AB. Theory and technology of engineering ceramics processing[M]. Beijing: National Defence Industry Press, 2006

[3]. Nishida Masako. Stress concentration [M]. Beijing: Mechanical Industry Press, 1986.

[4]. Tang XJ , Tian XL, WANG WL, et al. Study on fracture regulars and mechanisms of edge chipping for engineering ceramics based on energy[J]. Journal of Synthetic Crystals, 2013, 42(10):1-4

[5]. Scieszka S F. Edge failure as a means of concurrently estimating the abrasion and edge fracture resistance of hard-metals[J]. Tribology International, 2005,38(9): 834-842 